\title{
O HOMEM PÓS-MODERNO COMO VÍTIMA COLATERAL DA SOCIEDADE DE
} CONSUMO

\author{
Rafaela Baldissera ${ }^{1}$ \\ Liton Lanes Pilau Sobrinho ${ }^{2}$
}

\section{RESUMO}

O presente artigo tem como objetivo investigar se os padrões determinados pela sociedade de consumidores trazem impactos negativos ao ser humano enquanto ator social. Nesse sentido, por meio do método dedutivo e da técnica bibliográfica, discorre-se sobre o fato de o consumo ser um novo valor social e analisa-se quem seriam as vítimas colaterais da atual sociedade de consumo. Assim, ao verificar que as ações humanas estão sendo orientadas por mandamentos consumistas, reconhece-se a importância de uma educação para o consumo consciente e sustentável como pressuposto para aperfeiçoar um desenvolvimento humano mais responsável, pautado na igualdade e justiça social.

Palavras chaves: Consumismo; Consumo consciente; Sociedade; Sustentabilidade; Vítimas colaterais.

\section{THE POST-MODERN MAN AS A COLLATERAL VICTIM OF THE CONSUMER SOCIETY}

\begin{abstract}
This article aims to investigate if the patterns determined by the society of consumers bring negative impacts to the human being as a social factor. In this sense, through the deductive method and the bibliographical technique, we discuss the fact that consumption is a new social value and analyze who would be the collateral victims of the current consumer society. Thus, when verifying that human actions are guided by consumerist commands, the importance of education for conscious and sustainable consumption is recognized as a prerequisite for perfecting a more responsible human development, based on equality and social justice.
\end{abstract}

\footnotetext{
${ }^{1}$ Mestre em Direito pela Faculdade Meridional - IMED, linha de pesquisa Mecanismos de Efetivação da Democracia e da Sustentabilidade. Mestranda em Direito pela Universidade de Passo Fundo - UPF, linha de pesquisa Jurisdição Constitucional e Democracia. Especialista em Direito Processual Civil e Direito do Trabalho e Processo do Trabalho pela Faculdade Meridional (IMED). Especialista em Direito Notarial e Registral, Direito Previdenciário, Direito Civil e Direito Empresarial e Advocacia Empresarial pela Universidade Anhanguera Uniderp. Integrante do Grupo de Pesquisa Multiculturalismo e Pluralismo Jurídico. Integrante do Grupo de Pesquisa Ética, Cidadania e Sustentabilidade. Integrante do Grupo de Pesquisa Desafios da Sustentabilidade na Era Tecnológica: (Im)Possibilidade comunicacional e seus impactos na Saúde e Meio Ambiente. Passo Fundo/RS. Brasil.

2 Professor dos cursos de Mestrado e Doutorado no Programa de Pós-Graduação Stricto Sensu em Ciência Jurídica da Universidade do Vale do Itajaí. Professor do Programa de Pós-Graduação Stricto Sensu Mestrado em Direito da Universidade de Passo Fundo.Pós-doutor em Direito pela Universidade de Sevilha - US -Espanha. Doutor em Direito pela Universidade do Vale do Rio dos Sinos - UNISINOS (2008). Mestre em Direito pela Universidade de Santa Cruz do Sul - UNISC (2000). Possui graduação em Direito pela Universidade de Cruz Alta (1997). Passo Fundo/RS. Brasil.
} 
Keywords: Consumerism; Conscious Consumption; Society; Sustainability; Collateral Victims.

\section{INTRODUÇÃO}

Quando se trata de pensar numa sociedade ${ }^{3}$ que passou a viver em função do capital e sob a imposição de padrões consumistas, busca-se entender as posturas e as atitudes que possam ter contribuído para que o homem pós-moderno tenha começado a valorizar excessivamente o ato de consumir bens materiais, desprezando princípios que deveriam nortear a vida humana.

Nessa perspectiva, este artigo tem como objetivo principal analisar se os padrões determinados pela sociedade de consumidores trazem consequências negativas ao ser humano enquanto ator social. Em relação aos objetivos específicos, pretende-se: a) averiguar se o consumo é um novo valor social no século XXI; b) sinalizar quais são as vítimas colaterais da atual sociedade de consumidores; c) identificar a necessidade de uma educação direcionada ao consumo consciente e sustentável.

O problema jurídico formulado para a presente pesquisa questiona: a maneira como a atual sociedade de consumidores determina os padrões comportamentais impacta negativamente sobre o ser humano? A hipótese provisória para essa indagação sugere que o consumo, em sua ascensão, se reinventou como um vetor de orientação e inserção social, uma forma de organizar e categorizar a sociedade de consumidores segundo os níveis de consumo e, a partir desse cenário, diversos impactos negativos recaem sobre a vida social dos seres humanos, bem como no meio ambiente em que vivem.

Nessa contextualização, o agir humano ganha importância quando se trata de discutir comportamentos relacionados ao consumismo, pois, diante do sistema capitalista, a incessante busca por satisfação econômica impera na atual sociedade de consumidores. Logo, a tomada de consciência, por parte dos atores sociais, deve ser tratada como prioridade, visto que

\footnotetext{
3 “A sociedade, enquanto fenômeno humano, decorre da associação de homens, da vida em comum, fundada na mesma origem, nos mesmos usos, costumes, valores, cultura e história. Constitui-se sociedade no e pelo fluxo das necessidades e potencialidades da vida humana; o que implica tanto a experiência da solidariedade, do cuidado, quanto da oposição, da conflitividade. Organização e caos são pólos complementares de um mesmo movimento - dialético - que dá dinamismo à vida da sociedade". (DIAS, 2010, p. 487).
} 
pressupõe condutas mais responsáveis no sentido de estimular a formação de sujeitos empenhados na construção de um consumo sustentável.

O estudo considerou o método dedutivo, a partir de uma contextualização teórica, norteada em pesquisa bibliográfica para tratar, inicialmente, o consumo como um novo valor social no vigente século, em seguida, aborda-se sobre as vítimas colaterais da atual sociedade de consumidores e, por fim, expõe-se a necessidade de buscar uma educação direcionada a um consumo consciente e sustentável.

\section{RETRATO DO SÉCULO XXI: O CONSUMO COMO UM NOVO VALOR SOCIAL}

O consumo ${ }^{4}$, visualizado como uma prática de sobrevivência humana, em tese, não apresenta significativas ameaças ao meio ambiente, pois caracteriza uma das etapas do ciclo natural do ecossistema terrestre. No entanto, o advento da globalização e o crescimento do capitalismo provocaram mudanças na forma como o ser humano passou a desfrutrar de seu poder de consumo.

Segundo Bauman, após a revolução consumista - quando o ato de consumir passou a ser o propósito de vida dos seres humanos - o consumo entrou para um outro estágio, chamado de consumismo ${ }^{5}$, este configurado pelo excesso de consumo (BAUMAN, 2008, p. 38). Nesse cenário, a sociedade passou a desenvolver uma frequente necessidade de obter bens materiais, os quais se tornaram mais do que meros objetos, pois foram elevados a condição de potencializadores de sensações momentâneas de felicidade (BAUMAN, 2008, p. 60). Nessa linha de pensamento, Bauman ensina que:

O valor mais característico da sociedade de consumidores, na verdade seu valor supremo, em relação ao qual todos os outros são instados a justificar seu mérito, é uma vida feliz. A sociedade de consumidores talvez seja a única na história humana

\footnotetext{
${ }^{4}$ Para Bauman o consumo é "[...] algo banal, até mesmo trivial [...] é uma condição, e um aspecto, permanente e irremovível, sem limites temporais ou históricos; um elemento inseparável da sobrevivência biológica que nós humanos compartilhamos com todos os outros organismos vivos". (BAUMAN, 2008, p. 37).

${ }^{5} \mathrm{Na}$ visão de Bauman: "De maneira distinta do consumo, que é basicamente uma característica e uma ocupação dos seres humanos como indivíduos, o consumismo é atributo da sociedade. Para que uma sociedade adquira esse atributo, capacidade profundamente individual de querer, desejar, e almejar deve ser, tal como a capacidade de trabalho na sociedade de produtores, destacada ("alienada") dos indivíduos e reciclada/reificada numa força externa que coloca a "sociedade de consumidores" em movimento e a mantém em curso como uma forma específica de convívio humano, enquanto ao mesmo tempo estabelece parâmetros específicos para as estratégias individuais de vida que são eficazes e manipula as probabilidades de escolha e condutas individuais". (BAUMAN, 2008, p. 41).
} 
a prometer felicidade na vida terrena, aqui e agora e a cada "agora" sucessivo. Em suma, uma felicidade instantânea e perpétua [...]. (BAUMAN, 2008, p. 60).

Com essa nova roupagem, o consumo não se enquadra mais apenas como uma prática para suprir as necessidades básicas do ser humano. As reiteradas aquisições supérfluas passaram a funcionar como uma "válvula de escape", pois, a cada nova compra realizada, o sentimento repentino de felicidade acaba por adormecer as mágoas e as angústias humanas.

Dessa forma, mesmo que enfraquecidas, as emoções humanas não deixam de existir pelo fato de o indivíduo ter adquirido um novo bem de consumo. Por esse motivo, há uma grande e constante demanda por novos bens materiais, já que o frequente consumo demonstra estar diretamente relacionado com as dificuldades que o homem do século XXI enfrenta para superar suas aflições (BAUMAN, 2011, p. 162).

Nesse sentido, a marca característica da atual sociedade é a liquidez ${ }^{6}$ contida nas relações e nos sentimentos humanos (BAUMAN, 2001, p. 08). Assim, a sociedade de consumidores está alicerçada pelos pilares da insatisfação, do interesse pessoal e de uma grande acessibilidade a novos e remodelados produtos de consumo. Então, observa-se que o próprio ser humano retroalimenta um ciclo vicioso, no qual os bens de consumo são produzidos e lançados, em intervalos cada vez menores, para suprirem desejos humanos reinventados, bem como para criarem uma (quase) satisfação (BAUMAN, 2008, p. 44). Seguindo esse entendimento, Bauman revela que:

\begin{abstract}
A instabilidade dos desejos e a insaciabilidade das necessidades, assim como a resultante tendência ao consumo instantâneo e à remoção, também instantânea, de seus objetos, harmonizam-se bem com a nova liquidez do ambiente em que as atividades existenciais foram inscritas e tendem a ser conduzidas no futuro previsível. Um ambiente líquido-moderno é inóspito ao planejamento, investimento e armazenamento de longo prazo. De fato, ele tira do adiantamento da satisfação seu antigo sentido de prudência, circunspecção e, acima de tudo, razoabilidade. A maioria dos bens valiosos perde o brilho e sua atração com rapidez, e se houver atraso eles podem se tornar adequados apenas para o depósito de lixo, antes mesmo de terem sido desfrutados [...]. (BAUMAN, 2008, p. 45).
\end{abstract}

\footnotetext{
6 “[...] os líquidos, diferentemente dos sólidos, não mantêm sua forma com facilidade. Os fluídos, por assim dizer, não fixam o espaço nem prendem o tempo. Enquanto os sólidos têm dimensões espaciais claras, mas neutralizam o impacto e, portanto, diminuem a significação do tempo (resistem efetivamente a seu fluxo ou o tornam irrelevante), os fluídos não se atêm muito a qualquer forma e estão constantemente prontos (e propensos) a mudá-la; assim, para eles, o que conta é o tempo, mais do que o espaço que lhes toca ocupar; espaço que, afinal, preenchem apenas 'por um momento'. Em certo sentido, os sólidos suprimem o tempo; para os líquidos, ao contrário, o tempo é o que importa [...]”. (BAUMAN, 2001, p. 08).
} 
A partir dessas constatações, pode-se dizer que os integrantes da atual sociedade de consumidores são facilmente manipulados pelas estratégias econômicas, vez que, ao tentarem se adequar ao modelo de desenvolvimento capitalista, rendem-se a 'ronda diabólica ${ }^{, 7}$ do mercado de consumo e acabam por inventar desejos desnecessários e insatisfações injustificadas.

De fato, os avanços tecnológicos possibilitaram maior rapidez na produção e no lançamento de produtos ao mercado do consumo, contudo, por outro lado, a cada produto inaugurado, as mercadorias antigas são consideradas obsoletas por estarem fora dos novos padrões do mundo capitalista (BAUMAN, 2008, p. 44 e 45).

Diante disso, verifica-se que a lucratividade de muitas empresas está direcionada à manipulação da qualidade dos produtos de consumo, pois, ao reduzirem a durabilidade das mercadorias, as grandes corporações empresariais não precisam aguardar os desejos ou insatisfações dos consumidores finais para rentabilizarem seus ganhos financeiros, apenas esperam que os produtos - por eles fabricados - expirem o (programado) prazo de validade e necessitem ser substituídos por novos artefatos (MORAES, 2015, p. 58).

Essa técnica mercadológica abusiva é conhecida pelo nome de obsolescência $\operatorname{programada}^{8}$ e, embora seja muito usual, no Brasil, não são visualizadas fiscalizações e efetivas punições nesse sentido. Todavia, importante ressaltar que, recentemente, a França aprovou um artigo de lei para impedir que essa estratégia econômica continue prejudicando consumidores $^{9}$ (INSTITUTO BRASILEIRO DE DEFESA DO CONSUMIDOR, 2015, p. 01).

\footnotetext{
${ }^{7}$ Para Latouche "Três ingredientes são necessários para que a sociedade de consumo possa prosseguir na sua ronda diabólica: a publicidade, que cria o desejo de consumir; o crédito, que fornece os meios; e a obsolescência acelerada e programada dos produtos, que renova a necessidade deles. Essas três molas propulsoras da sociedade de crescimento são verdadeiras 'incitações-ao-crime"'. (LATOUCHE, p. 17 e 18).

${ }^{8}$ A obsolescência planejada (ou programada) pode ser conceituada sob três aspectos, quanto à qualidade, função e desejabilidade. Assim, quanto ao primeiro aspecto refere que "É a estratégia utilizada pelo produtor, que deliberadamente projeta o tempo de vida útil do produto, desenvolvendo técnicas e/ou materiais de qualidade inferior, para reduzir a durabilidade do produto". Já em relação ao aspecto da função diz que "é a estratégia que torna um produto obsoleto com o lançamento de outro produto no mercado, ou do mesmo produto com melhoramentos, capaz de executar a mesma função do antigo de forma mais eficaz". Por fim, a definição conforme a desejabilidade, infere que "é a estratégia para tornar um produto defasado em decorrência da sua aparência, seu design, deixando-o menos desejável”. (MORAES, 2015, p. 58).

9 A notícia informada pelo Instituto Brasileiro de Defesa do Consumidor revela: "Dois anos de prisão e uma multa de 300 mil euros (cerca de R\$ 1,1 milhão) para a empresa que limitar a vida útil dos aparelhos eletrônicos e eletrodomésticos que produz, técnica que tem o nome de obsolescência programada. A notícia é real, mas vem de longe daqui. Jornais e sites franceses contaram a boa nova para quem luta contra a prática por considerar que ela contribui - e muito - para o aquecimento global, já que quanto mais se produz, mais se está tirando um naco do meio ambiente [...] De acordo com o documento aprovado sobre a obsolescência programada, serão passíveis
} 
A fabricação de produtos com durabilidade enfraquecida, projetados para serem inutilizados em um curto (e predeterminado) prazo, demonstra ser um abuso e uma afronta aos direitos do consumidor (MORAES 2015, p. 52 e 53), bem como um desrespeito aos valores ético-ambientais e de sustentabilidade.

Impulsionar um frequente círculo de 'compra e descarte' de bens de consumo auxilia na materialização de impactos ambientais negativos ${ }^{10}$, pois, além de requisitar maior extração de meios naturais (LEFF, 2009, p. 51), também contribui para o aumento da quantidade de lixo e resíduos tóxicos no planeta terra.

A obsolescência programada é uma dinâmica de mercado que integra uma lógica econômica plenamente calculada, pois, apesar de agravar os problemas ambientais (MORAES, 2015, p. 77), a crescente demanda por bens de consumo é vista (pelos olhos de empresários e economistas despreocupados com as reais consequências do crescimento econômico ilimitado) como uma estratégia rentável que contribui para a economia local e/ou mundial $^{11}$. Na acepção de Bauman:

[...] a necessidade de substituir objetos de consumo "defasados", menos que plenamente satisfatórios e/ou não mais desejados está inscrita no design dos produtos e nas campanhas publicitárias calculadas para o crescimento constante das vendas. A curta expectativa de vida de um produto na prática e na utilidade proclamada está incluída na estratégia de marketing e no cálculo de lucros: tende a ser preconcebida, prescrita e instilada nas práticas dos consumidores mediante a apoteose das novas ofertas (de hoje) e a difamação das antigas (de ontem). (BAUMAN, 2008, p. 31).

\footnotetext{
de multa e estão comprometidas 'todas as técnicas pelas quais uma empresa visa, através da concepção do produto, a diminuir "propositalmente" a duração da vida útil ou da utilização potencial de tal produto para aumentar sua taxa de substituição. Estas técnicas podem incluir a introdução voluntária de um defeito, fragilidade, paralisação programada ou prematura, limitação técnica, impossibilidade de reparação ou não compatibilidade'[...]". (INSTITUTO BRASILEIRO DE DEFESA DO CONSUMIDOR, 2015, p.01).

${ }^{10}$ No entendimento de Leff "O que marcou as formas dominantes de produção e de crescimento econômico a partir da Revolução Industrial é o caráter determinante da apropriação capitalista e da transformação tecnológica dos recursos naturais em relação a seus processos de formação e regeneração, o que repercutiu no esgotamento progressivo dos recursos abióticos e na degradação do potencial produtivo dos ecossistemas criadores dos recursos bióticos [...]”. (LEFF, 2009, p. 51).

${ }^{11}$ Moraes assinala que "Na década de 1950, um destacado desenhista industrial dos Estados Unidos, Brooks Stevens, declarou expressamente que toda a economia americana era baseada na prática da obsolescência planejada, vez que o mercado industrial fabricava e divulgava seus produtos de forma a torná-los rapidamente velhos, antiquados, obsoletos, convencendo assim as pessoas a descartá-los pouco tempo após a compra. Segundo o autor, isto não representava um desperdício organizado, mas uma sólida contribuição à economia norte-americana [...] embora a economia crescimentista (modelo econômico ocidental capitalista hegemônico) tenha sido e ainda seja mantida também por outras estratégias, não há dúvidas de que a obsolescência planejada, em todas as suas formas, gera grande parte da demanda consumista de nossa época". (MORAES, 2015, p. 50 e $51)$.
} 
Assim, observa-se que, enquanto novos bens de consumo são lançados nas prateleiras físicas ou virtuais, outros milhões de produtos são automaticamente descartados por consumidores ávidos por comprar. No entanto, as estratégias econômicas, realizadas para impulsionar essa intensa rotatividade de mercadorias, acabam por desconsiderar fatores essenciais, como, por exemplo, os limites da natureza ${ }^{12}$. (LATOUCHE, 2009, p. 27).

Logo, entende-se que o consumo excessivo não se compatibiliza com a finitude do mundo natural e, além disso, traz inúmeras consequências ao próprio ser humano, visto que este já se encontra no rol das vítimas ${ }^{13}$ dos desastres ambientais, fortalecidos pelos novos padrões de consumo.

Ademais, nota-se que o homem pós-moderno ${ }^{14}$ é pressionado a se adaptar às demandas impostas pela voracidade do mercado e do consumismo. Assim, a dinâmica consumista, além de promover impactos ambientais no existir humano, também provoca impactos sociais, vez que a padronização social, organizada segundo os vetores do mercado de consumo, conduz a cenários de desigualdade, segregação ${ }^{15}$ e exclusão social.

Desse modo, enquanto as "necessidades" humanas forem induzidas pelo mercado de consumo, os indivíduos terão que se recriarem ininterruptamente para serem inseridos na remodelada sociedade de consumidores, na qual a identidade pessoal de cada ser humano está subordinada à aprovação social e à capacidade de seguir as regras do mundo capitalizado.

\footnotetext{
${ }^{12}$ Latouche revela que "Nosso crescimento econômico excessivo choca-se com os limites da finitude da biosfera. A capacidade de regeneração da Terra já não consegue acompanhar a demanda: o homem transforma os recursos em resíduos mais rápidos do que a natureza consegue transformar esses resíduos em novos recursos. (LATOUCHE, 2009, p. 27). Grifos originais da obra.

${ }^{13}$ Segundo Freitas, "O que não faz o menor sentido é persistir na matriz comportamental da degradação e do poder neurótico sobre a natureza, não somente porque os recursos naturais são finitos, mas porque tal despautério faz milhões de vítimas no caminho. É altamente falacioso tentar escapar das responsabilidades pelos desequilíbrios ambientais, atribuindo exclusivamente a culpa à natureza, mecanismo clássico de fuga pusilânime [...]". (FREITAS, 2012, p. 64)

14 "A Pós-modernidade é um processo (histórico e cultural) em formação. É uma vivência que não consegue afirmar a partir de seus narradores ou de uma concepção teórica. O enaltecimento ou a crítica a esse movimento torna-se uma atividade complexa, pois o cotidiano está impregnado de especulações (mitos, fantasias) em detrimento de informações empíricas que comprovem a existência desse período histórico [...]" (AQUINO, 2016, p. 117).

${ }^{15}$ Para Aquino e Zambam: “[...] Existe, em qualquer território deste planeta, uma aguda cegueira moral motivada, especialmente, pela (aparente) neutralidade e objetividade das ações econômicas, as quais transformaram o consumo num valor de orientação (e segregação) social denominado consumismo [...]" (AQUINO; ZAMBAM, 2016, p. 117)
} 


\section{QUEM SE ENQUADRA COMO VÍTIMA COLATERAL DA ATUAL SOCIEDADE DE CONSUMIDORES?}

Atualmente, seguir as imposições do mercado de consumo tornou-se critério de inserção social $^{16}$. A busca por um status social e a necessidade de inclusão impulsiona o hiperconsumismo, pois, a sociedade contemporânea "[...] promove, encoraja ou reforça a escolha de um estilo de vida e uma estratégia existencial consumistas e rejeita todas as opções culturais alternativas [...]”. (BAUMAN, 2008, p, 71).

O consumo excessivo de bens materiais representa o passaporte ${ }^{17}$ para que um indivíduo participe (ou não) de um determinado grupo social (BAUMAN, 2008, p. 82). Nesse sentido, estar bem vestido, com roupas da 'moda' (de marcas conhecidas no mercado nacional e internacional) já se transformou em critério de visibilidade e inserção social.

No entanto, a sociedade de consumidores vai muito além, requer que os indivíduos pós-modernos ${ }^{18}$ estejam permanentemente à frente do seu tempo e, por esse motivo, o homem do século XXI deve estar prontamente preparado para comprar os lançamentos dos telefones celulares, automóveis, computadores, televisores, notebooks, ou qualquer outro bem material que possa ser ostentado.

$\mathrm{Na}$ sociedade de consumidores, o ser humano tornou-se um fantoche, pois está escravizado aos padrões impostos pelo mercado de consumo, bem como subordinado às estratégias econômicas (como, por exemplo, a chamada obsolescência programada, já comentada em capítulo anterior).

Assim, ao comportar-se conforme os ditames do mundo consumista, o ser humano busca ser incluído nessa nova sociedade líquido-(pós)moderna ${ }^{19}$, vez que o medo de se tornar

\footnotetext{
${ }^{16}$ Ou seja: "O acesso aos bens, embora não seja uma exigência absoluta para a avaliação da realização de uma pessoa ou do equilíbrio social, é um importante indicativo para que um indivíduo tenha condições de participar de diferentes ambientes e instâncias sociais e, assim, alcançar certos níveis mínimos de aceitação". (ZAMBAM, 2012, p. 54).

${ }^{17}$ Segundo Bauman: "Para entrar na sociedade de consumidores e receber um visto de residência permanente, homens e mulheres devem atender às condições de elegibilidade definidas pelos padrões do mercado [...]". (BAUMAN, 2008, p. 82).

18 “[...] Não se rejeita (totalmente) a Modernidade, mas se vivem os valores da Pós-modernidade indagando-se, constantemente, sobre os efeitos dessa transição histórica, pois existem mudanças (profundas) nos valores e nas crenças que fundamentavam as relações sociais modernas que, hoje, não respondem satisfatoriamente às exigências da Sociedade contemporânea". (AQUINO, 2016, p. 119).

${ }_{19}$ No entendimento de Bauman: "[...] A modernidade líquida é uma civilização de excesso, redundância, desperdício e eliminação de refugos. Na sucinta e expressiva formulação de Ricardo Petrella, as tendências globais de hoje direcionam as 'economias rumo à produção do efêmero e do volátil - por meio da maciça
} 
indesejado e excluído, em mundo tão globalizado, propõe um padrão homogêneo de vivência social, no qual a tendência é o progressivo hiperconsumo ${ }^{20}$. Para Bauman:

A cultura consumista é marcada por uma pressão constante para que sejamos alguém
mais. Os mercados de consumo se concentram na desvalorização imediata de suas
antigas ofertas, a fim de limpar a área da demanda pública para que novas ofertas a
preencham. Engendram a insatisfação com a identidade adquirida e o conjunto de
necessidades pelo qual se define essa identidade. Mudar de identidade, descartar o
passado e procurar novos começos, lutando para renascer - tudo isso é estimulado
por essa cultura como um dever disfarçado de privilégio. (BAUMAN, 2008, p. 128).

O consumo, visualizado como um novo valor da sociedade, propõe uma estandardização social, na qual os sujeitos são forçados a se moldarem às exigências impostas pelo mercado de consumo. Consequentemente, como resultado dessa lógica consumista, observa-se a fragmentação social, a qual diferencia os indivíduos pelo seu poder aquisitivo e nível de consumo.

Logo, observa-se que a cultura consumista prioriza o 'ter' no lugar do 'ser' ${ }^{21} \mathrm{e}$, nessa inversão de valores, o próprio ser humano é quem acaba sendo desvalorizado. Assim, a racionalidade econômica ${ }^{22}$, internalizada no pensamento da atual sociedade de consumidores, demonstra refletir negativamente sobre o meio ambiente, bem como intensifica as desigualdades sociais ${ }^{23}$ (LEFF, 2010, p. 64).

Além do mais, o estilo de vida hiperconsumista do homem pós-moderno, traz um “[...] caráter facilmente descartável das identidades individuais e dos laços inter-humanos que estão representados na cultura contemporânea como a substância da liberdade individual [...]” (BAUMAN, 2011, p. 163). Logo, a fórmula do descarte, aplicável aos produtos de consumo,

redução da vida útil de produtos e serviços (empregos temporários, de horário flexível e de meio período)' [...]”'. (BAUMAN, 2011, p. 189).

20 "[...] O hiperconsumo do indivíduo contemporâneo "turbo-consumidor" redunda numa felicidade ferida ou paradoxal. Os homens nunca alcançaram tamanho grau de derrelição. A indústria dos "bens de consolação" tenta em vão remediar essa situação [...]". (LATOUCHE, 2009, p. 22 e 23).

${ }_{21}$ Para Pereira, Calgaro e Pereira, "[...] se ultrapassou a denominada sociedade hiperconsumista, dando azo a uma sociedade consumocentrista. Nesse viés, o consumo passa a ser o elemento principal das atividades humanas, deslocando o ser para o ter e, posteriormente, para o aparentar. Dessa forma, o consumo se torna o centro da sociedade contemporânea, onde o consumidor vai buscar todas as possibilidades de sua nova razão de viver. Consumir é existir". (PEREIRA, CALGARO, PEREIRA, 2016, p. 267).

22 "Essa dominação da racionalidade econômica sobre todas as outras formas de racionalidade é a essência do capitalismo. Deixando a si mesmo, ele chegará à extinção da vida e, assim, de si próprio. Se ele deve ter um sentido, só poderá ser o de criar as condições de sua própria supressão”. (GORZ, 2010, p. 43).

${ }^{23} \mathrm{Na}$ visão de Bauman "[...] Todas as variedades de sociedade líquida moderna estão cada vez mais reconciliadas com a permanência da desigualdade econômica e social [...]”. (BAUMAN, 2011, p. 125). 
estendeu seus horizontes para os atores sociais dessa era líquido-(pós)moderna, pois, sob o olhar de Bauman, ao adequarem-se aos comandos da lógica do mercado de consumo, os seres humanos passaram a mercantilizar a sua própria vida ${ }^{24}$ (BAUMAN, 2008, p. 20).

Dessa forma, Löwy acredita que a objetivação dos elementos naturais, bem como dos seres humanos está diretamente relacionada a uma crise civilizacional capitalista industrial moderna (LÖWY, 2012, p. 147). Nessa linha de pensamento, Bauman utiliza a citação de Dany-Robert Dufour, para referir que, além de o capitalismo estar aumentando a capacidade de mercantilizar elementos da natureza - como, por exemplo, os animais, as plantas, a água, o solo - também está expandido sua área de atuação para questões particulares da vida humana - tais como: a opção sexual, o modo de pensar, a individualidade - de modo que o ser humano se torne prisioneiro dos julgamentos valorativos da economia de mercado (BAUMAN, 2010, p. 48).

À vista disso, entende-se que a perspectiva capitalista determina o valor das coisas, dos meios naturais e, inclusive, das condutas humanas. Por esse motivo, a preocupação da era pós-moderna volta-se ao modelo de desenvolvimento econômico adotado pelo homem, no qual as ações humanas estão direcionadas à exploração desmedida de tudo o que possa ser transformado em mercadoria e, essa incessante busca por expansão econômica acaba por desprezar valores e princípios que deveriam nortear a vida do ser humano.

Nesse viés, pode-se afirmar que o crescimento econômico está atrelado ao desempenho do mercado de consumo, o qual se apoia na vulnerabilidade dos consumidores para maximizar seus lucros (BAUMAN, 2011, p. 174 e 175). O fato é que essa dinâmica econômica capitalista desencadeou uma verdadeira síndrome consumista ${ }^{25}$, que já causa consequências danosas ao ser humano, pois, além de frustação, insatisfação e sentimento de

\footnotetext{
24 “[...] A característica mais proeminente da sociedade de consumidores - ainda que cuidadosamente disfarçada e encoberta - é a transformação dos consumidores em mercadorias [...]". (BAUMAN, 2008, p. 20).

25 " "[...] a síndrome consumista degradou a duração e elevou e efemeridade. Ela ergue o valor da novidade acima do valor da permanência. Reduziu drasticamente o espaço de tempo que separa não apenas a vontade de sua realização (como muitos observadores, inspirados ou enganados por agências de crédito, já sugeriram), mas o momento do nascimento da vontade do momento de sua morte, assim como a percepção da utilidade e vantagem das posses de sua compreensão como inúteis e precisando de rejeição. Entre os objetos do desejo humano, ela colocou o ato da apropriação, a ser seguido com rapidez pela remoção do lixo, no lugar que já foi atribuído à aquisição de posse destinadas a serem duráveis e a terem um aproveitamento duradouro". (BAUMAN, 2008, p. 111).
} 
exclusão, o homem também passou a se reinventar como uma mercadoria vendável ${ }^{26}$ (BAUMAN, 2008, p. 75 e 76).

No entanto, mesmo com toda essa pressão para que o ser humano consuma reiteradamente, alguns atores sociais não conseguem (ou não querem) se enquadrar aos padrões da cultura consumista. Desse modo, “[...] aqueles que se movem apenas pelo que acreditam precisar e que são ativados pelo desejo de satisfazer essas necessidades são consumidores falhos e, por isso, também desterrados sociais" (BAUMAN, 2011, p. 153).

Os homens refugados são desprezados pela sociedade por não estarem padronizados às atuais tendências capitalistas do mercado de consumo. Assim, a estereotipização do consumidor perfeito (ou ideal) conduz a cenários de segregação social, bem como salienta as desigualdades. Nesse entendimento, Bauman revela que

[...] Os consumidores falhos donos de recursos demasiado escassos para reagirem de
forma adequada aos "apelos" dos mercados de bens de consumo, ou mais
exatamente a seus passes sedutores, são pessoas "desnecessárias" para a sociedade
de consumidores, que estaria melhor sem elas. Numa sociedade que avalia seu
sucesso ou fracasso pelas estatísticas do PIB (ou seja, a soma total de dinheiro que
troca de mãos nas transações de compra e venda), esses consumidores deficientes e
defeituosos são descartados por serem perigosos. O pressuposto tácito subjacente a
esse raciocínio é, uma vez mais, a fórmula "não há consumidor sem mercadoria". A
comodificação precede o consumo e controla o acesso ao mundo dos consumidores.
É preciso primeiro se tornar uma mercadoria para ter uma chance razoável de
exercer os direitos e cumprir os deveres de um consumidor [...]. (BAUMAN, 2008,
p. 88 e 89).

Aprisionados em uma sociedade determinada a fabricar consumidores compulsivos, pois quanto mais o sujeito consome, maior será seu nível de visibilidade e aprovação social, os seres humanos buscam (muitas vezes, de forma frustrada) seguirem os padrões culturais de consumo fundamentados em uma lógica estritamente econômica.

Nesse aspecto, observa-se que, quando a vida se organiza segundo os vetores do consumismo, não é possível observar a viabilidade de ideais como liberdade, justiça e igualdade, vez que na sociedade de consumidores nada dura por muito tempo, pois o descarte

\footnotetext{
26 "Consumir", portanto, significa investir na afiliação social de si próprio, o que, numa sociedade de consumidores, traduz-se em "vendabilidade": obter qualidades para as quais já existe uma demanda de mercado, ou reciclar as que já se possui, transformando-as em mercadorias para as quais a demanda pode continuar sendo criada. A maioria das mercadorias oferecidas no mercado de consumo deve sua atração e seu poder de recrutar consumidores ávidos a seu valor de investimento, seja ele genuíno ou suposto, anunciado de forma explícita ou indireta [...] O consumo é um investimento em tudo que serve para o "valor social" e a auto-estima do indivíduo. (BAUMAN, 2008, p. 75 e 76)
} 
de objetos, de sentimentos, de relações e de pessoas inadequadas faz parte das regras do jogo da pós-modernidade líquida ${ }^{27}$. Sendo assim, temendo o descarte e buscando a inclusão social, os indivíduos procuram se espelharem em quem ostenta mais. Seguindo essa linha de raciocínio, Kempf revela que:

[...] em cada classe, os indivíduos adotam como modelo o comportamento vigente na camada social superior, que mostra o que se deve e é bacana fazer. A camada social imitada, por sua vez, se inspira da camada situada acima dela na escala da fortuna. Esta imitação se reproduz de baixo para cima, de tal forma que a classe situada no topo define o modelo cultural geral daquilo que é prestigioso, daquilo que se impõe aos demais. O que ocorre em uma sociedade muito desigual? Um imenso desperdício é gerado, porque a dilapidação material da oligarquia - em si, refém da competição ostentadora - serve de exemplo para toda a sociedade. Cada um no seu nível, no limite das suas rendas, tenta adquirir os bens e sinais mais valorizados. Mídia, propaganda, filmes, novelas e revistas de "famosos" são as ferramentas de difusão do modelo cultural dominante. (KEMPF, 2012, p. 231 e 232).

Nesse cenário, verifica-se que a cultura consumista imposta pela sociedade capitalista já reflete negativamente sobre seus próprios cidadãos, pois, no momento em que o consumismo se transformou num vetor de orientação social exacerbado e sem limites, (todos) os homens pós-modernos tornaram-se vítimas colaterais dessa desordenada forma de consumo.

Portanto, o imperativo ético do século XXI, bem como seu maior desafio, é promover a conscientização da coletividade, a fim de que as reiteradas práticas consumistas, encorajadas pelo modelo capitalista, sejam mitigadas. Desse modo, faz-se necessário avançar na promoção da educação para um consumo conscientemente sustentável como uma alternativa para alterar a mentalidade consumista e materialista, atualmente, enraizada no ser humano.

\footnotetext{
27 “[...] Como consumidores, não juramos lealdade permanente à mercadoria que procuramos e adquirimos para satisfazer as nossas necessidades ou desejos; e continuamos a usar esses serviços enquanto eles atenderem às nossas expectativas, porém não mais que isso - ou até que deparemos com outra mercadoria que prometa satisfazer os mesmos desejos mais plenamente que o anterior. Todos os bens de consumo, incluindo dos descritos como 'duráveis', são intercambiáveis e dispensáveis; na cultura consumista - inspirada pelo consumo e a serviço dele -, o tempo decorrido entre a compra e o descarte tende a se comprimir até o ponto em que as delícias derivadas do objeto de consumo passam de seu uso para a apropriação. A longevidade do uso tende a encolher, e os incidentes de rejeição e descarte tendem a se tornar mais freqüentes à medida que se exaure com mais rapidez a capacidade de satisfazer (e de continuar desejáveis) dos objetos. Uma atitude consumista pode lubrificar as rodas da economia, e ela joga areia nos rolamentos da moral" (BAUMAN e DONKSIS, 2014, p. 23).
} 


\title{
3 A NECESSIDADE DE UMA EDUCAÇÃO DIRECIONADA AO CONSUMO CONSCIENTE E SUSTENTÁVEL
}

O consumismo ocupa posição de destaque no atual cenário mundial e, por esse motivo, uma educação para o consumo sustentável é apresentada como um caminho necessário a ser trilhado, visto que a sociedade de consumidores precisa estar orientada por um dever ético ${ }^{28}$ de sustentabilidade social ${ }^{29}$ e ambiental ${ }^{30}$.

Ocorre que o consumidor, integrante da sociedade líquido-(pós)moderna, está sendo guiado pelos mandamentos do capitalismo, sistema considerado verdadeiro reprodutor de desigualdades sociais ${ }^{31}$. Nesse sentido, uma série de inseguranças e incertezas rondam o futuro da humanidade, pois o consumo desordenado já demonstra trazer consequências danosas para o ser humano. Para Souza e Stohrer:

\begin{abstract}
Compreender as implicações ambientais do consumo praticado é o primeiro passo do consumidor em direção a sua libertação das amarras do consumismo. A fim de que possa, de fato, tomar decisões conscientes a respeito de suas aquisições, o indivíduo precisa conhecer a maneira pela qual seus bens foram produzidos. É cediço que o dinheiro direciona as aspirações da atual sociedade. Entretanto, para além da manutenção dos empregos e do poder aquisitivo das pessoas é primordial entender que não haverá planeta para gastar o dinheiro se o padrão acelerado de produção e consumo se mantiver. Neste sentido, tem-se que o consumo consciente deve ser a consequência da racionalização a respeito da perpetuação da vida no planeta, nela compreendida a vida humana, mas também a coexistência dos milhares de espécies que compõem a natureza. (SOUZA; STOHRER, 2016, p. 117).
\end{abstract}

Dessa maneira, observa-se que o consumismo traz consequências danosas ao mundo natural, mas, também gera impactos sociais negativos ao ser humano, pois, como referiu-se

\footnotetext{
28 "O momento é de frear o consumo e de simplificar a existência. Isso é postura ética. A análise de mercado não pode substituir a ética" (NALINI, 2015, p. 176)

29 "Em sua dimensão social, a sustentabilidade reclama: (a) o incremento da equidade intra e intergeracional; (b) a gestão aperfeiçoada de processos, que assegure condições favoráveis ao florescimento virtuoso das potencialidades humanas, especialmente no atinente à educação de qualidade [...]; e (c) o engajamento na causa do desenvolvimento que perdura e faz a sociedade apta a sobreviver, a longo prazo, com respeito ao valor intrínseco dos demais seres vivos. (FREITAS, 2012, p. 18).

30 "Em sua dimensão ambiental, a sustentabilidade faz perceber que: (a) não pode haver qualidade de vida e longevidade digna em ambiente degradado; (b) sem prejuízo da "modernização ambiental", o hiperconsumismo haverá de ser confrontado, notadamente nos países ricos; (c) no limite, não pode sequer perdurar a espécie humana, sem o zeloso resguardo da sustentabilidade ambiental, em tempo útil”. (FREITAS, 2012, p. 18).

31 “[...] No mundo, a produção acumulada, bem como o padrão de vida medida em bens materiais e serviços aumentou para um grande número de pessoas. Mas, atualmente a situação do capitalismo é volátil, porque aumentou as desigualdades sociais e de classe, numa economia global". (HARVEY, 2011, p. 54).
} 
em capítulo anterior, os males trazidos pelos elevados padrões de consumo promovem desigualdades, angústias, medos, frustações e desvalorizam os próprios consumidores.

A partir de um comportamento racional e ético, o consumo consciente, direcionado aos ideais de sustentabilidade ${ }^{32}$, precisa ser tratado como uma questão de ordem pública, pois o ser humano, cidadão da atual sociedade de consumidores, deve ter uma postura de corresponsabilidade no que tange aos problemas sociais ${ }^{33}$ e ambientais ${ }^{34}$ causados pelo estilo de vida pós-moderno dos homens. Nesse passo, Pereira, Calgaro e Pereira salientam que:

É importante o desenvolvimento de mudanças na racionalidade que se dá a partir de
políticas públicas voltadas a uma educação ambiental direcionada a um consumo
consciente. Nesse aspecto, o Estado não pode ser mínimo, mas forte o suficiente
para conseguir implantar essas políticas. No que se refere ao Estado, esse tem a
obrigação de atuar conforme a responsabilidade socioambiental, pois é o ente que
possui, também, deveres para com a coletividade e não com o capital transnacional.
Como se observa na Constituição Federal de 1988, o Estado representa o interesse
da sociedade e de seu povo e não interesses de grandes corporações. (PEREIRA;
CALGARO; PEREIRA, 2016, p. 277).

Desse modo, a educação para o consumo consciente e sustentável ${ }^{35}$ revela-se como uma alternativa para proporcionar o conhecimento sobre a vida sustentável, impulsionando uma base educacional de raiz socioambiental, a qual contribuirá para a criação de um senso de responsabilidade ambiental (DOBSON, 2003, p. 177).

\footnotetext{
${ }^{32}$ Para Boff a sustentabilidade pode ser conceituada como "[...] toda ação destinada a manter as condições energéticas, informacionais, físico-químicas que sustentam todos os seres vivos, especialmente a Terra viva, a comunidade de vida e a vida humana, visando sua continuidade e ainda atender as necessidades da geração presente e das futuras, de tal forma que o capital natural seja mantido e enriquecido em sua capacidade de regeneração, reprodução e coevolução". (BOFF, 2012, p. 107).

33 "Atualmente, novos desafios surgem a cada dia, merecendo destaque os desastres naturais decorrentes das mudanças climática, entre eles: os alarmantes níveis de pobreza mundial, como no continente africano; o desenvolvimento tecnológico-científico voraz, além da decadência dos sistemas morais e políticos. Tais desafios fomentam o crescimento da corrupção, aumentando, ainda mais, as desigualdades entre os povos. Percebe-se que as ameaças que assombram e aterrorizam a humanidade, nos dias de hoje, têm conexão direta e indireta com o progresso - processo de modernização. No cenário de desenvolvimento industrial a todo a vapor, objetivando atender ao mercado consumista, a natureza é concebida unicamente como forma de exploração, de onde se extraem os recursos necessários aos meios de produção; nada mais, além disso". (VIEIRA; REZENDE, 2017, p. 317).

34 "O efeito devastador da produção industrial desenfreada, realizada sempre em nome do progresso da economia e da satisfação do público consumidor, destrói matas, florestas, animais, polui rios, água, mar, ar e solo, o que compromete o direito ao meio ambiente ecologicamente equilibrado, necessário à sobrevivência da própria espécie humana". (VIEIRA; REZENDE, 2015, p. 70).

35 "O consumo consciente e responsável é a principal manifestação de responsabilidade social do cidadão. O consumidor deve ser incentivado a fazer com que o seu ato de consumo seja também um ato de cidadania, escolhendo em que mundo quer viver. Essa mudança de comportamento é um processo que requer sensibilização e mobilização social, e a informação acaba sendo fundamental [...]". (PEREIRA; CALGARO; PEREIRA, 2012, p. 68).
} 
A educação para um consumo responsável ${ }^{36}$ deve ter bases na igualdade e na justiça, sendo necessário ensinar aos cidadãos a tarefa de desenvolver a solidariedade, objetivando a união dos atores sociais na busca de uma materialização, a longo prazo, da sustentabilidade, nas suas dimensões social e ambiental.(DOSBON, 2003, p. 106 e 107).

Nesse sentido, observa-se que o poder do Estado se manifesta como uma importante ferramenta na promoção da educação ambiental ${ }^{37} \mathrm{e}$, consequentemente, seu caráter interventivo também pode/deve ser utilizado para o ensino de um consumo consciente e sustentável, no sentido de formar consumidores mais responsáveis, que valorizem princípios morais, sociais e ambientais. Para tanto, Bauman revela que o objetivo de um Estado social:

[...] é defender a sociedade contra o "dano colateral" que o princípio guia da vida causaria caso não fosse monitorado, controlado e constrangido. Esse Estado foi indicado para proteger a sociedade da multiplicação de fileiras de "vítimas colaterais" do consumismo - os excluídos, os desterrados, as subclasses. Sua tarefa é resguardar a solidariedade humana da erosão e proteger o sentimento de responsabilidade ético do desvanecimento. (BAUMAN, 2011, p. 148).

Portanto, as responsabilidades devem ser conjugadas por todos os integrantes do corpo social ao lado do Estado, vez que a efetivação de políticas públicas, direcionadas à educação para um consumo compatível com a sustentabilidade, depende do empenho do Poder Estatal, mas o cumprimento e a experimentação de práticas éticas e conscientes de consumo precisam da colaboração de toda a coletividade.

Dessa forma, a partir da conscientização do consumo responsável, a vida sustentável pode começar a ter significado prático no cotidiano do homem pós-moderno e, com isso, há a possibilidade de os seres humanos deixem de ser enquadrados como vítimas colaterais da atual sociedade líquida e passem a figurar como consumidores conscientes em um novo modelo de sociedade, na qual a justiça, igualdade, fraternidade e solidariedade serão considerados os valores máximos.

\section{CONSIDERAÇÕES FINAIS}

\footnotetext{
36 "Observa-se que a educação para o consumo pode ser desenvolvida na sociedade através de palestras aos consumidores, cursos e palestras aos fornecedores, atendimento e palestras para estudantes, atividades com crianças, pesquisas e publicações, dentre outros meios informativos, atingindo, assim, as atuais e futuras gerações [...] Nesse passo, importante desenvolver-se aqui a importância dessa educação, tanto para nosso equilíbrio social, bem como cultural, de maneira que também desenvolva nosso meio ambiente. Em razão disso, buscamos a implantação de conceitos de equidade e justiça social [...]" (PAUSE, 2015, p. 92).

${ }_{37}$ Artigo 225, § $1^{\circ}$, VI. BRASIL. Constituição (1988). Constituição da República Federativa do Brasil. Brasília, DF: Senado, 1988.
} 
Por ser um valor intrínseco das necessidades humanas, o consumo originou-se como uma prática trivial, no entanto, neste século, passou a ser enquadrado com um novo padrão de valorização social. Nesse cenário, o consumo cedeu espaço ao consumismo, o qual marcou posição prioritária em detrimento do meio ambiente e de valores sociais, cada vez mais, descartados.

Desse modo, constatou-se que os impactos sociais e ambientais estão sendo causados pelos padrões comportamentais dos seres humanos, os quais direcionam sua existência terrena para ampliarem ganhos financeiros, satisfazerem frequentes desejos de consumo e serem inseridos em uma sociedade padronizada.

Observou-se que, ao priorizar o crescimento econômico, o homem contemporâneo redirecionou suas condutas para um excessivo e frequente consumo, que, além de auxiliar na exploração do mundo natural, também contribui para enquadrar o ser humano no rol de vítimas colaterais de uma sociedade de consumidores compulsivos e frustrados. A partir dessas constatações, a hipótese de solução restou confirmada, pois indicou que o consumo se consagrou como um valor social, impactando negativamente sobre aspectos sociais da vida humana e desprezando os limites da natureza.

Não obstante as consequências de um estilo hiperconsumista estarem provocando impactos negativos aos seres humanos, a viabilização de práticas para um consumo consciente e sustentável é uma utopia concreta, pois se os homens pós-modernos se desprenderem do sentimento consumista que, atualmente, move as ações humanas, a construção de uma sociedade socioambiental, que determine novos valores ao ser humano, pode estar concretizada em um futuro próximo.

\section{REFERÊNCIAS}

AQUINO, Sérgio Ricardo Fernandes de. As raízes do direito na pós-modernidade. Itajaí: ed. Da UNIVALI, 2016.

AQUINO, Sérgio Ricardo Fernandes de; ZAMBAM, Neuro José. As contradições do capitalismo no século XXI e sua metamorfose pela democracia e justiça. Scientia Iuris, Londrina, v. 20, n. 2, p. 107-140, jul. 2016. Disponível em:

<http://www.uel.br/revistas/uel/index.php/iuris/article/view/22711>. Acesso em: 10 de abril de 2017. 
BAUMAN, Zygmunt. Modernidade líquida. Tradução de Plínio Dentzien. Rio de Janeiro: Jorge Zahar, 2001.

BAUMAN, Zygmunt. Vida para o consumo: a transformação das pessoas em mercadorias. Tradução de Carlos Alberto Medeiros. Rio de Janeiro: Zahar, 2008.

BAUMAN, Zygmunt. Capitalismo parasitário: e outros temas contemporâneos. Tradução Eliana Aguiar. Rio de Janeiro: Jorge Zahar, 2010.

BAUMANN, Zygmunt. A ética é possível num mundo de consumidores? Tradução de Alexandre Werneck. Rio de Janeiro: Zahar, 2011.

BAUMAN, Zygmunt; DONSKIS, Leonidas. Cegueira moral: a perda da sensibilidade na modernidade líquida. Tradução de Carlos Alberto Medeiros. Rio de Janeiro: Zahar, 2014.

BOFF, Leonardo. Sustentabilidade: o que é - o que não é. Petrópolis, RJ: Vozes, 2012.

DIAS, Maria da Graça dos Santos. Sociedade. In: BARRETO, Vicente de Paulo. Dicionário de filosofia política. São Leopoldo, (RS): Editora da UNISINOS, 2010.

DOBSON, Andrew. Citizenship and the Environment. New York: Oxford University Press, 2003.

FREITAS, Juarez. Sustentabilidade: direito ao futuro. Belo Horizonte: Fórum, 2012.

HARVEY, David. O enigma do capital e as crises do capitalismo. Tradução de João Alexandre Peschanski. São Paulo: Boitempo, 2011.

INSTITUTO BRASILEIRO DE DEFESA DO CONSUMIDOR. França aprova artigo de lei que pune empresa que praticar obsolescência programada. 2015. Disponível em: http://www.idec.org.br/em-acao/noticia-do-consumidor/franca-aprova-artigo-de-lei-que-puneempresa-que-praticar-obsolescencia-programada. Acesso em: 10 de abril de 2017.

LATOUCHE, Serge. Pequeno tratado do decrescimento sereno. Tradução de Cláudia Berliner. São Paulo: Martins Fontes, 2009.

LEFF, Enrique. Epistemologia ambiental. Tradução de Sandra Valenzuela. São Paulo, Cortez, 2010.

LEFF, Enrique. Ecologia, capital e cultura: a territorialização da racionalidade ambiental. Tradução de Jorge E. Silva. Petrópolis - RJ: Vozes, 2009.

MORAES, Kamila Guimarães. Obslescência planejada e direito (in) sustentabilidade do consumo à produção de resíduos. Porto Alegre: Livraria do Advogado, 2015. 
NALINI, José Renato. Ética Ambiental. Revista, atualizada e ampliada. São Paulo: Editora Revista dos Tribunais, 2015.

PAUSE, Ana Paula de Oliveira. O Direito Constitucional ao Meio Ambiente Saudável através da Educação para o Consumo: a abordagem das garantias constitucionais do consumidor diante do Princípio da Sustentabilidade, resultado da Educação para o Consumo. In: KERBER, Gilberto; BOFF, Salete Oro; JESUS, José Lauri Bueno. Educação para o consumo sustentável e prevenção do superendividamento. Campinas, SP: Millennium Editora, 2015.

PEREIRA, Agostinho Oli Koppe; CALGARO, Cleide; PEREIRA, Henrique Mioranza Koppe. Consumocentrismo e os seus reflexos socioambientais na sociedade contemporânea. Revista Direito Ambiental e sociedade, v. 6, n. 2, p. 264-279, 2016.

PEREIRA, Agostinho Oli Koppe; CALGARO, Cleide; PEREIRA, Henrique Mioranza Koppe. A sustentabilidade numa sociedade hiperconsumista. In: PILAU SOBRINHO, Liton Lanes. Consumo e sustentabilidade. Passo Fundo: Ed. Universidade de Passo Fundo, 2012.

VEIGA, José Eli da; ISSBERNER, Liz-Rejane. Decrescer crescendo. In: LÉNA, Philippe; NASCIMENTO, Elimar Pinheiro. Enfrentando os limites do crescimento: sustentabilidade, decrescimento e prosperidade. Rio de Janeiro: Garamond, 2012.

VIEIRA, Gabriella de Castro; REZENDE, Elcio Nacur. Sociedade de risco: consumismo e impactos ambientais. In: SILVEIRA, Clóvis Eduardo Malinverni; SOBRINHO, Sérgio Francisco Carlos Graziano. Direito, risco e sustentabilidade: abordagens interdisciplinares. Caxias do Sul/RS: Educs, 2017.

VIEIRA, Gabriella de Castro; REZENDE, Elcio Nacur. A Responsabilidade Civil Ambiental decorrente da Obsolescência Programada. Revista Brasileira de Direito, Passo Fundo, v. 11, n. 2, p. 66-76, jul.-dez 2015. Disponível em:

<https://seer.imed.edu.br/index.php/revistadedireito/article/view/838>. Acesso em: 30 de março de 2017.

SOUZA, Maria Claudia da Silva Antunes de; STOHRER, Camila Monteiro Santos. Consumo Consciente como mecanismo da Sustentabilidade. In: BENACCHIO, Marcelo; GARCIA, Marcos Leite; ARCE, Gustavo. Direito e sustentabilidade. Florianópolis: CONPEDI, 2016.

ZAMBAM, Neuro. Amartya Sen: liberdade, justiça e desenvolvimento sustentável. Passo Fundo: IMED, 2012. 